\title{
Efficacy of oral sarolaner for the treatment of generalized demodicosis in dogs
}

\author{
Eficácia do sarolaner oral no tratamento da demodiciose \\ canina generalizada
}

\author{
Flávia Clare Goulart de Carvalho** (D), Natália Lôres Lopes² (1D, Marília Alves Machado³ (D), Alexandre Merlo4 (D) \& \\ Julio Israel Fernandes ${ }^{5}$ (1) \\ 'Veterinarian, PhD, Professor. Centro Universitário de Valença - UNIFAA and Universidade Iguaçu - UNIG, RJ, Brasil \\ ² Veterinarian, Programa de Pós-Graduação em Medicina Veterinária - UFRRJ, Seropédica, RJ, Brasil \\ ${ }^{3}$ Veterinarian, Programa de Pós-Graduação em Ciências Veterinárias - UFRRJ, Seropédica, RJ, Brasil \\ ${ }^{4}$ Veterinarian, MSc. Zoetis, SP, Brasil \\ ${ }^{5}$ Veterinarian, PhD. Departamento de Medicina e Cirurgia Veterinária - UFRRJ, Seropédica, RJ, Brasil
}

\begin{abstract}
The aim of this study was to report the efficacy of oral sarolaner in dogs diagnosed with generalized demodicosis. Twenty-seven dogs criteria by deep skin parasitological were treated with $2 \mathrm{mg} / \mathrm{kg}$ oral sarolaner on days $0,+30,+60$ and +90 . The criteria used for parasitological cure was the presence of two consecutive negative deep skin scraping 30 days apart. The clinical parameters were recorded before treatment and every 30 days until day +90 . On day $+30,77,7 \%$ of animals presented first negative skin scraping for Demodex sp., and on day +60 , all animals treated presented at least one negative skin scrape and remained negative until the end of the study. On day $+30,7,41 \%$ of animals presented clinical improvement followed by $74,07 \%$ of remission on day +60 , On day $+90,88,8 \%$ of animals presented complete improve. Sarolaner was efficient in treating demodicosis an could also be and excellent option when macrociclic lactones are controindicated.
\end{abstract}

Keywords: dogs, efficacy, isoxazolines, Demodex canis.

\section{Resumo}

O objetivo do estudo foi reportar a eficácia do sarolaner administrado por via oral em cães portadores de demodiciose generalizada. Foram tratados vinte e sete cães portadores de demodiciose generalizada, diagnosticados a partir de raspado cutâneo, com sarolaner na dose de $2 \mathrm{mg} / \mathrm{kg}$ nos dias 0, +30, +60 e +90. O critério utilizado para cura parasitológica foi a obtenção de dois raspados negativos consecutivos com intervalo de 30 dias. Os parâmetros clínicos foram registrados antes do tratamento e a cada 30 dias, até o dia + 90. No dia +30,77,7\% dos animais apresentaram um primeiro raspado negativo para Demodex sp., e no dia +60 todos os animais medicados apresentaram pelo menos um raspado negativo, permanecendo negativos até o final do período observacional. No dia +30 , 7,41\% dos animais apresentaram remissão clínica, seguido de 74,07\% de remissão no dia +60. No dia +90, 88,8\% dos animais apresentaram remissão completa. Sarolaner foi eficaz no tratamento da demodiciose canina generalizada e pode ser uma excelente opção, principalmente quando as lactonas macrocíclicas são contraindicadas.

Palavras-chave: cães, eficácia, Isoxazolinas, Demodex canis.

\section{Introduction}

Canine demodicosis is a common cutaneous condition caused by the overpopulation of Demodex canis in the hair follicles and sebaceous glands. (Pereira et al., 2012; Pereira et al., 2015). It can be classified as localized and generalized according to the extent of the lesions. The localized form has less than five lesions, with spontaneous remission. The generalized form may affect a particular region completely or may manifest as more than five lesions spread along the body (Scott et al., 1995; Paradis, 1999). Diagnosis can be established by investigating the skin scrapings (Miller et al., 2013). Multiple negative skin scrapings and the resolution of clinical signs signal the end of treatment (Mueller et al., 2012). Macrocyclic lactones, such as avermectins and milbemycins, can be used as acaricidal therapy. (Kosh et al., 2012) However, their adverse effects are principally related to neurotoxicity, including depression, stupor, coma, ataxia, mydriasis, tremors, emesis, drooling, and seizures (Singh et al., 2011). They are also contraindicated in breeds with a ABCB1-1 (MDR-1) mutation (Kosh et al., 2012). Amitraz, a miticidal drug, is not indicated as first-line therapy
How to cite: Carvalho F. C. G., Lopes N. L., Machado M. A., Merlo A., \& Fernandes J. I. (2019). Efficacy of oral sarolaner for the treatment of generalized demodicosis in dogs. Brazilian Journal of Veterinary Medicine, 41, e102219. doi: 10.29374/2527-2179. bjvm102219.

Financial support: None.

Conflict of interests: No conflict of interests declared concerning the publication of this article.

Received: February 04, 2019

Accepted: May 05, 2019.

The study carried out at the small animal dermatology sector of UFRRJ and in private veterinary clinics, Seropédica, RJ, Brasil.

\section{*Correspondence}

Flavia Clare Goulart de Carvalho

R Dr Alvaro Soares, 85, Madruga

CEP 27700-000 - Vassouras (RJ), Brasil

E-mail: flaviaclare@gmail.com
Copyright Carvalho et al. This is an Open Access article distributed under the terms of the Creative Commons Attribution Non-Commercial License which permits unrestricted non-commercial use, distribution, and reproduction in any medium provided the original work is properly cited. 
(Kosh et al., 2012). Its adverse effects include ataxia and depression (Sartor \& Santarem, 2006), in addition to hyperglycemia and transient sedation (Kosh et al., 2012).

Isoxazolines constitute a new class of ectoparasiticides for companion animals, against fleas and ticks (Mctier et al., 2016a). These drugs are rapidly absorbed and distributed by the systemic circulation (Tanrattana, 2017). The compound sarolaner is part of this group and was identified as the most potent isoxazoline (Mctier et al., 2016a). This drug has high palatability and is fully and voluntarily consumed within 1 minute in 90.5\% of cases (Becskei et al., 2016). No severe adverse effects were observed by earlier studies (Becskei et al., 2016; Mctier et al., 2016a; Six et al., 2016a; Six et al., 2016b).

A single dose of $2 \mathrm{mg} / \mathrm{kg}$ sarolaner (Mctier et al., 2016b) has a 30-month efficacy against ticks and fleas. Its use for the treatment of parasitic skin diseases including, sarcoptic mange (Becskei et al., 2016), otodectic mange (Six et al., 2016c,) and demodicosis (Six et al., 2016c; Becskei et al., 2018), was also considered.

Premature discontinuation of therapy is a reason for failure of treatment of canine demodicosis (Singh et al., 2011). Since sarolaner is a safe (Mctier et al., 2016a) and palatable drug (Becskei et al., 2016), which is easily administered, the aim of this study was to report the treatment efficacy oral sarolaner in dogs with demodicosis.

\section{Material and methods}

The study was a retrospective study designed in Veterinary Hospital and the Dermatology Service, under the protocol 4851170317 and the Dermatology Service at the Veterinary Clinic Veterinary Clinic in Brazil, under the protocol 040/2018.

Twenty-seven dogs with lesions involving a particular region of the body (pododemodicosis) or at least five localized lesions were included in the study. Generalized demodicosis was confirmed by observation of Demodex mites in deep skin scrapings. Lesions were classified as papules, macules, pustules, alopecia, hypothricosis, erythema, comedones, scales, and crusts. Signalment of breed, sex and age were recorded. Dogs who were also under immunosuppressant therapy, those treated with acaricidal therapy for 60 days or less, or dogs younger than 12 weeks were not included.

The dogs were treated with oral sarolaner at a dose of $2.0 \mathrm{mg} / \mathrm{kg}$ every 30 days for $3 \mathrm{months}$, as per the manufacturer's instruction. The dogs were bathed with benzoyl peroxide $2.5 \%$ shampoo every 7 days. Dogs with superficial or deep pyoderma received systemic antimicrobial therapy.

Deep skin scrapings were obtained from all dogs on the first day before treatment and repeated every 30 days. A scalpel blade was used deep skin scrapings were obtained from five affected areas in each dog. The skin was pinched and released a few time, then an oily scalpel blade applied to the skin until capillary bleeding was observed. The material sampled was smeared out on a microscope glass slide with the addition of mineral oil and covered with a coverslip. Slides were examined after skin scrapings were performed, under a microscope with 10x objective for resence of Demodex mites. Resolution of infection was considered only when two deep skin scrapings tested negative at a 30-day interval. The clinical signs and dermatological lesions were recorded before and during treatment, every 30 days.

\section{Results}

Twenty-seven dogs, 17 (62.96\%) males and 10 (37.04\%) females, were diagnosed with generalized demodicosis. Age varied from three months to 14 years old. Dogs aged under one year old (12dogs/44.44\%), between one and seven years old (11dogs/40.74\%) and above seven years old (4dogs/14.81\%). The dogs in this study were of mixed breed (n=9; 33.3\%); English bulldogs ( $n=3 ; 11.1 \%)$; German Shepherds, Labrador Retrievers, Pinscher, and Pitbulls ( $n=2 ; 7.41 \%$ each); and Belgian Malinois, Cane Corsos, French Bulldogs, Great Danes, Poodles, Weimaraners, and Yorkshire ( $\mathrm{n}=1 ; 3.71 \%$ each).

Cutaneous lesions observed included alopecia (24/88.8\%), crusts (15/55.55\%), erythema (12/44.44\%), hyperkeratosis (7/25.93\%), hyperpigmentation (6/22.22\%), seborrhea, pustules and erosion (5/18.52\% each) epidermal collarette and excoriation (4/14.81\% each) lichenification, and scales (3/11.1\% each). 
The deep skin scrapings of all patients tested positive for Demodex mites before treatment. Thirty days after treatment, 21 (77.77\%) dogs already showed negative results for Demodex; only $6(22.22 \%)$ dogs showed positive results. On day 60 , all dogs showed negative results for mites, and no positive skin scrapings were seen on day 90, including the 6 dogs that showed their first negative result for skin scrapings on day 60, presenting $100 \%$ resolution over a period of 60 days. The animals had generalized lesions.

Only 2 (7,41\%) of 27 dogs had no skin lesions after 30 days of treatment. However, on day 60, 20 (74.07\%) dogs presented with no lesions and only 7 (2.59\%) did not undergo recovery. Within 90 days, 24 (88.88\%) were fully recovered, but 3 (11.1\%) dogs still had dermatological lesions.

\section{Discussion}

In this study, a greater number of younger animals exhibited clinical signs, suggesting an early age of onset (Delayte, 2016). The clinical signs mainly reported in this study are commonly associated with this disease (Mueller et al., 2012; Miller et al., 2013).

The results of this study demonstrate the efficacy of sarolaner in treating generalized demodicosis, similar to reports on sarolaner (Six et al., 2016c; Becskei et al., 2018) and other isoxazolines (Fourie et al., 2015; Beugnet et al., 2016; Snyder et al., 2017; Duangkaew et al., 2018), with resolution of the condition in all dogs. Most patients (77\%) exhibited the first negative result on examination of skin scrapings after 30 days of treatment. These data are consistent with the findings of Six et al. (2016c), who reported that $75 \%$ of the dogs on day 29 were free of live mites in the sarolaner-treated group and that after 60 days of treatment, $100 \%$ of cases showed negative results. In cases treated with fluralaner, another isoxazoline, similar results were observed, with 100\% resolution after 56 days of treatment (Fourie et al. 2015). The time required to achieve the first negative result on examination of deep skin scraping was shorter than that observed for other drugs like ivermectin (Delayte et al., 2006). Sarolaner is effective and rapid acting in cases of ectoparasites like ticks and fleas (Mctier et al., 2016b) and in demodicosis. This observation was supported by a rapid reduction in the numbers of live mites observed by other authors (Six et al., 2016c). It is not possible to compare these data as mite counts were not performed in this study. Sarolaner is the only drug in the isoxazoline group in Brazil that is indicated for treatment of this dermatopathy by the manufacturer.

In this study, resolution of the parasitic infection (characterized by two deep skin scrapings with 30 day-interval) was achieved by all dogs within 90 days, unlike Becskei et al. (2018), who obtained results within 180 days.

Skin lesions improved in the majority of dogs as observed by other authors (Six et al., 2016c; Becskei et al., 2018). Two of the 3 patients that still showed clinical signs were concurrently diagnosed with leishmaniosis, which could have caused immunosuppression and promoted the proliferation of demodectic mites. Identifying the underlying systemic disease is an essential part of successful treatment of demodicosis (Mueller et al., 2012).

\section{Conclusion}

Sarolaner was shown to be a safe and effective drug for the treatment of generalized canine demodicosis. It could be a useful alternative to conventional treatment, especially for animals with contraindications to conventional drugs.

\section{References}

Becskei, C., Cuppens, O., \& Mahabir, S. P. (2018). Efficacy and safety of sarolaner against generalized demodicosis in dogs in European countries: a non-inferiority study. Veterinary Dermatology, 29(3), 203-e72. http://dx.doi. org/10.1111/vde.12526. PMid:29423956.

Becskei, C., De Bock, F., Illambas, J., Mahabir, P., Farkas, R., \& Six, R. H. (2016). Efficacy and safety of a novel oral isoxazoline, sarolaner (Simparica ${ }^{\mathrm{TM}}$ ) in the treatment of naturally occurring flea and tick infestations in dogs presented as veterinary patients in Europe. Veterinary Parasitology, 222, 56-61. http://dx.doi.org/10.1016/j. vetpar.2016.02.017. PMid:26928658.

Beugnet, F., Halos, L., Larsen, D., \& de Vos, C. (2016). Efficacy of oral afoxoloner for the treatment of canine generalized demodicosis. Parasite, 23, 14. http://dx.doi.org/10.1051/parasite/2016014. PMid:27012161. 
Delayte, E. H. (2016). Demodiciose canina. In C.E. Larsson \& R. Lucas. Tratado de medicina externa- dermatologia veterinária (1a ed.). São Caetano do Sul: Interbook.

Delayte, E. H., Otsuka, M., Larsson, C. E., \& Castro, R. C. C. (2006). Eficácia das lactonas macrocíclicas sistêmicas (ivermectina e moxidectina) na terapia da demodicidose canina generalizada. Arquivo Brasileiro de Medicina Veterinária e Zootecnia, 58(1), 31-38. http://dx.doi.org/10.1590/S0102-09352006000100006.

Duangkaew, L., Larsuprom, L., Anukkul, P., Lekcharoensuk, C., \& Chen, C. (2018). A field trial in Thailand of the efficacy of oral fluralaner for the treatment of dogs with generalized demodicosis. Veterinary Dermatology, 29(3), 208-e74. http://dx.doi.org/10.1111/vde.12524. PMid:29424108.

Fourie, J. J., Liebenberg, J. E., Horak, I. G., Taenzler, J., Heckeroth, A. R., \& Frénais, R. (2015). Efficacy of orally administered fluralaner (Bravecto ${ }^{\mathrm{TM}}$ ) or topically applied imidacloprid/moxidectin (Advocate ${ }^{\circledR}$ ) against generalized demodicosis in dogs. Parasites \& Vectors, 8(1), 187. http://dx.doi.org/10.1186/s13071-015-0775-8. PMid:25881320.

Kosh, S. N., Torres, S. M. F., \& Plumb, D. C. (2012) Canine and feline dermatology drug handbook (1st ed.). Iowa: Wiley-Blackwell.

Mctier, T. L., Chubb, N., Curtis, M. P., Hedges, L., Inskeep, G. A., Knauer, C. S., Menon, S., Mills, B., Pullins, A., Zinser, E., Woods, D. J., \& Meeus, P. (2016a). Discovery of sarolaner: A novel, orally administered, broadspectrum, isoxazoline ectoparasiticide for dogs. Veterinary Parasitology, 222, 3-11. http://dx.doi.org/10.1016/j. vetpar.2016.02.019. PMid:26961590.

McTier T.L., Six R.H., Fourie J.J., Pullins A., Hedges L., Mahabir S.P. \& Myers M.R. 2016b. Determination of the effective dose of a novel oral formulation of sarolaner (Simparica) for the treatment and month-long control of fleas and ticks on dogs. Vet Parasitol. 222:12-17.

Miller, W. H., Griffin, C. E., \& Campbell, K. L. (2013) Muller and Kirk's small animal dermatology (7th ed.). St Louis: Elsevier.

Mueller, R. S., Bensignor, E., Ferrer, L., Holm, B., Lemarie, S., Paradis, M., \& Shipstone, M. A. (2012). Treatment of demodicosis in dogs: 2011 clinical practice guidelines. Veterinary Dermatology, 23(2), 86-e21. http://dx.doi. org/10.1111/j.1365-3164.2011.01026.x. PMid:22329600.

Paradis, M. (1999). New approaches to the treatment of canine demodicosis. Veterinary Clinics: Small Animal Practice, 29(6), 1425-1436. http://dx.doi.org/10.1016/S0195-5616(99)50136-8. PMid:10563009.

Pereira, A. V., Pereira, S. A., Gremião, I. D. F., Campos, M. P., \& Ferreira, A. M. R. (2012). Comparison of acetate tape impression with squeezing versus skin scraping for the diagnosis of canine demodicosis. Australian Veterinary Journal, 9O(11), 448-450. http://dx.doi.org/10.1111/j.1751-0813.2012.00994.x. PMid:23106326.

Pereira, D. T., Castro, L. J. M., Centenaro, V. B., Amaral, A. S., Krause, A., \& Schmidt, C. (2015). Skin impression with acetate tape in Demodex canis and Scarcoptes scabiei var. vulpes diagnosis. Arquivo Brasileiro de Medicina Veterinária e Zootecnia, 67(1), 49-54. http://dx.doi.org/10.1590/1678-6869.

Sartor, I. F., \& Santarem, V. A. (2006). Agentes empregados no controle de ectoparasitos. In H. S. Spinosa, S. L. Gorniak, \& M. M. Bernardi. Farmacologia Aplicada à Medicina Veterinária (4a ed.). Rio de Janeiro: Guanabara Koogan.

Scott, D. W., Miller, W. H., \& Griffin, C. E. (1995) Parasitic skin diseases. In D. W. Scott, W. H. Miller \& C. E. Griffin (Ed.), Muller and Kirk's Small Animal Dermatology (5th ed., pp. 417-432). Philadelphia: W B Saunders.

Singh S.K., Kumar M., Jadhav R.K. \& Saxen S.K. 2011. An update on therapeutic management of Canine Demodicosis. Vet. World. 4(1):41-44.

Six, R. H., Everett, W. R., Young, D. R., Carter, L., Mahabir, S. P., Honsberger, N. A., Myers, M. R., Holzmer, S., Chapin, S., \& Rugg, J. J. (2016a). Efficacy of a novel oral formulation of sarolaner (Simparica ${ }^{\mathrm{TM}}$ ) against five common tick species infesting dogs in the United States. Veterinary Parasitology, 222, 28-32. http://dx.doi.org/10.1016/j. vetpar.2015.12.023. PMid:26935819.

Six, R. H., Young, D. R., Myers, M. R., \& Mahabir, S. P. (2016b). Comparative speed of kill of sarolaner (Simparica ${ }^{\mathrm{TM}}$ ) and afoxolaner (NexGard ${ }^{\circledR}$ ) against induced infestations of Ixodes scapularis on dogs. Parasites \& Vectors, 9(1), 1-6. http://dx.doi.org/10.1186/s13071-016-1307-x. PMid:26876891.

Six, R. H., Becskei, C., Mazaleski, M. M., Fourie, J. J., Mahabir, S. P., Myers, M. R., \& Slootmans, N. (2016c). Efficacy of sarolaner, a novel oral isoxazoline, against two common mite infestations in dogs: Demodex spp. and Otodectes cynotis. Veterinary Parasitology, 222, 62-66. http://dx.doi.org/10.1016/j.vetpar.2016.02.027. PMid:26971196.

Snyder, D. E., Wiseman, S., \& Liebenberg, J. E. (2017). Efficacy of lotilaner (Credelio ${ }^{\mathrm{TM}}$ ), a novel oral isoxazoline against naturally occurring mange mite infestations in dogs caused by Demodex spp. Parasites \& Vectors, 10(1), 532. http://dx.doi.org/10.1186/s13071-017-2472-2. PMid:29089049.

Tanrattana, C. (2017). Practical and update management of canine demodicosis. Wetchasan Sattawaphaet, 47, S55-S56. 